\title{
Desempenho e Rendimento de Carcaça de Quatro Grupos Genéticos de Codornas para Produção de Carne ${ }^{1}$
}

\author{
Cleusa Móri², Edivaldo Antônio Garcia ${ }^{3}$, Ana Cláudia Pavan ${ }^{4}$, Adriana Piccinin 5 , Carla Cachoni \\ Pizzolante ${ }^{6}$
}

\begin{abstract}
RESUMO - Para avaliar o desempenho e rendimento de carcaça de quatro grupos genéticos de codornas de corte de 1 a 42 dias de idade, foram utilizadas 1.200 codornas distribuídas em delineamento inteiramente casualizado com quatro tratamentos (A, B, C, D) e cinco repetições de 60 aves por parcela. Uma vez por semana as aves foram pesadas para avaliação do ganho médio de peso e consumo médio de ração, além do registro da mortalidade. Aos 42 dias de idade, foram identificados e abatidos 10 machos por parcela, para avaliação do rendimento de carcaça e dos cortes cárneos. No período 1 a 42 de idade, o grupo genético C apresentou maiores peso e ganho médio de peso que os demais grupos. Contudo, para consumo médio de ração, conversão alimentar e mortalidade, não foram observadas diferenças entre os grupos genéticos. Para peso vivo, peso de carcaça, rendimento de carcaça e porcentagem de peito, não foram encontradas diferenças estatísticas entre os grupos genéticos. Para porcentagem de asa, coxa e carne de peito, o grupo genético D apresentou maior valor que os demais grupos. Considerando os resultados obtidos, os grupos genéticos de codornas para produção de carne utilizados no Brasil apresentam diferenças no seu desempenho produtivo e nos cortes cárneos.
\end{abstract}

Palavras-chave: abate, carne de codornas, desempenho, grupo genético, rendimento de carcaça

\section{Performance and Carcass Yield of Four Quail Genetic Groups Selected for Meat Production}

\begin{abstract}
The study aimed to evaluate the performance and carcass yield of four quail genetic groups male and females. The birds were grown until 42 days old. A thousand and two hundred day old quails were distributed in a completely randomized design with four treatments (A, B, C and D) and five replicates of 60 birds each. The birds were weighed once a week in order to evaluate weight gain and feed consumption. Mortalities were recorded daily. At 42 days, ten male quails from each replicate were identified and slaughtered to evaluate the yield of carcass and parts. In the period from 1 to 42 days, genetic group $\mathrm{C}$ showed higher values of body weight. Group $\mathrm{C}$ showed the higher values for weight gain in the period from 1 to 42 days. No differences concerning the results of feed consumption, feed efficiency, mortality, body weight, carcass weight, carcass yield and breast percentage were observed among the groups. Genetic group D showed higher values for wings, legs and breast meat percentage. It was concluded that there are differences of performance and carcass and parts yield among the quail genetic groups selected for meat production presented on Brazilian market.
\end{abstract}

Key Words: carcass yield, genetic group, meat quail, performance, slaughter

\section{Introdução}

Em virtude do aumento do consumo mundial de carne, pesquisadores estão buscando alternativas que possam satisfazer as novas exigências de produtos de origem animal e, uma delas está relacionada à produção de codornas de corte.

A criação de codornas para produção de carne é uma boa alternativa para obtenção de proteína de origem animal, pois suas instalações não necessitam de grandes investimentos, uma vez que este animal é pequeno e ocupa pouco espaço e sua produção de dejetos é inferior à das criações animais convencionais, agredindo menos o meio ambiente. Entretanto, pouco se conhece sobre o potencial produtivo de codornas de corte no Brasil e sobre os custos de produção, tornando seu preço elevado e pouco competitivo no mercado varejista em relação a outras aves.

No Brasil, a produção de codornas é predominantemente voltada para produção de ovos, pois a falta de

\footnotetext{
${ }^{1}$ Projeto financiado pela FAPESP. Parte da Dissertação de Mestrado da primeira autora.

${ }^{2}$ Aluna de Pós-Gradução em Zootecnia (Doutorado) da Faculdade de Medicina Veterinária e Zootecnia - UNESP Botucatu. (cleusa_mori@fca.unesp.br).

3 Professor do Departamento de Produção e Exploração Animal da Faculdade de Medicina Veterinária e Zootecnia - UNESP Botucatu. (egarcia@fca.unesp.br).

4 Zootecnista. Mestre em Produção e Nutrição Animal pela Faculdade de Medicina Veterinária e Zootecnia FMVZ/UNESP - Botucatu (ana.pavan@fca.unesp.br).

5 Aluna de Pós-Graduação em Genética (Doutorado) do Instituto de Biociências - UNESP - Botucatu.

${ }^{6}$ Pesquisadora da Agência Paulista de Tecnologia dos Agronegócios - UPD Brotas.
} 
material genético adequado, a precariedade de dados sobre o desempenho e as exigências nutricionais fazem com que criadores explorem a produção de carne de forma pouco organizada e empírica.

Por esses motivos, a empresa Perdigão ${ }^{\circledR}$ lançou recentemente no mercado uma linha de produtos, desenvolvida a partir de ovos importados da França, que inclui carne de codornas in natura, elevando em $60 \%$ sua produção no ano de 2002 para atender também o mercado externo.

Nesse sentido, torna-se grande o desafio para pesquisadores e profissionais desenvolverem técnicas de produção e manejo que possibilitem maior representatividade da espécie no mercado brasileiro, garantindo futuramente o grande sucesso obtido na exploração de frangos de corte.

As codornas para corte apresentam taxa de crescimento e peso final muito maiores que as de postura, o que permite atingirem peso adequado ao abate em idade bastante precoce. Segundo Marks (1991), um dos fatores que contribui para este crescimento rápido é o maior consumo de alimentos nos primeiros estádios de vida. Este autor observou que a correlação entre velocidade de crescimento e consumo de ração é alta em várias aves domésticas, entre elas frangos e codornas de corte.

Diversos autores constataram diferenças de peso entre linhagens de codornas selecionadas para corte (Lepore \& Marks, 1971; Campion et al., 1982; Baumgartner et al., 1985; Caron et al., 1990; Marks, 1993; Oguz et al., 1996), ao observarem variações de $113,4 \mathrm{~g}$ até $217,0 \mathrm{~g}$ aos 56 dias de idade. Nestor et al. (2002), estudando o efeito da seleção para aumento de ganho de peso em seis linhagens de codornas japonesas, obtiveram valores para machos e fêmeas, respectivamente, às quatro semanas, de 213,1 e 225,0 g. A conversão, a eficiência alimentar e o ganho de peso são significativamente afetados pela linhagem ou variedade das aves (Panda et al., 1987; Marks, 1991;1993; Ardiningsasi et al., 1992; Michalska \& KorzynskaNowak, 1992; Steigner et al., 1992).

Garcia (2002) relatou que as carcaças obtidas de codornas não destinadas à produção de carne eram muito pequenas (70 a $110 \mathrm{~g}$ ) e a carne das fêmeas era relativamente dura, por se tratar de aves de aproximadamente um ano de idade. No entanto, a carne dessas aves é normalmente comercializada no nordeste do Brasil e tem boa aceitação neste mercado.
Além do uso de linhagem específica, a utilização de machos e fêmeas no plantel também pode ter impacto na eficiência de produção e/ou na característica do produto final. Caron et al. (1990), além de caracterizarem as diferenças entre linhas, também ressaltaram a importância das diferenças de peso entre os sexos, em que as fêmeas foram mais pesadas que os machos de mesma idade.

De acordo com Almeida (2001), os machos da linhagem italiana apresentam boa aptidão para corte, apresentando melhor desempenho que os da linhagem japonesa, caracterizando-se por maior ganho de peso médio e melhor conversão alimentar. Segundo o autor, codornas italianas são superiores às codornas japonesas em relação ao ganho de peso médio semanal, porém fêmeas da linhagem japonesa apresentam maior precocidade para postura do primeiro ovo que fêmeas da linhagem italiana.

Além da relevância da linhagem sobre o desempenho produtivo, os efeitos de sexo são também aparentes sobre as características de carcaça. Caron et al. (1990) salientam que machos mais pesados produzem carcaças mais pesadas, enquanto fêmeas mais pesadas são aquelas mais maduras sexualmente, por isso, possuem aparelho reprodutivo mais pesado. Oguz et al. (1996) relatam que, em razão do dimorfismo sexual durante o período de crescimento em aves, machos possuem peso maior que fêmeas. Entretanto, em codornas, as fêmeas são mais pesadas que os machos, diferença que ocorre por volta da terceira e quarta semana de idade, sendo atribuída pelo peso dos ovários e fígado.

Baumgartner et al. (1985) verificaram melhor rendimento de peito em linhagem de codornas destinadas à produção de carne que em linhagens voltadas para produção de ovos. Rendimentos de pernas, asas e coxas foram semelhantes para as duas linhagens. Caron et al. (1990) encontraram melhores rendimentos de peito e pernas para linhagens selecionadas em relação ao grupo controle e Oguz et al. (1996) não obtiveram diferenças nos rendimentos de peito e pernas entre linhagens.

Assim, em virtude da baixa disponibilidade de informações, torna-se necessária uma avaliação do potencial produtivo e das características de interesse econômico da linhagem italiana introduzida no país.

Objetivou-se com o presente estudo avaliar o desempenho e rendimento de carcaça de quatro grupos genéticos de codornas para produção de carne, criadas no período de 1 a 42 dias de idade. 


\section{Material e Métodos}

O experimento foi realizado nas instalações do setor de Avicultura, localizado na Fazenda Experimental Edgárdia, da Faculdade de Medicina Veterinária e Zootecnia da UNESP, campus de Botucatu. Foram utilizadas 1.200 codornas de um dia de idade, $50 \%$ de cada sexo, adquiridas das granjas Coração de Leão (grupo genético C), localizada em Brasília, DF, Molino Blanco (grupo genético D), localizada no município de São Lourenço da Serra, SP, e da Granja Suzuki (grupos genéticos A e B), localizada em São Paulo.

As aves foram alojadas de 1 a 42 dias de idade em galpão de cria medindo $15 \mathrm{~m}$ de comprimento por $4 \mathrm{~m}$ de largura, coberto com telhas de cimento amianto e provido de cortinas plásticas em suas laterais. Internamente, o galpão foi equipado com 20 gaiolas metálicas com $100 \mathrm{~cm}$ de comprimento x $80 \mathrm{~cm}$ de profundidade e $35 \mathrm{~cm}$ de altura, dispostas em duas fileiras com um corredor de serviço. Cada gaiola teve seu piso revestido com jornal, sobre o qual foi colocada tela plástica, para evitar fuga das aves e possíveis traumatismos nas pernas das mesmas. A lateral de cada gaiola teve revestimento de papelão de $15 \mathrm{~cm}$, também para se evitar fugas. O piso abaixo de cada gaiola foi coberto com $5 \mathrm{~cm}$ de maravalha para absorção da umidade dos dejetos das aves. Cada gaiola possuía em sua parte superior uma campânula elétrica com lâmpada infravermelha de 250 watts de potência para aquecimento das aves até os 21 dias de idade. Foram utilizados dois bebedouros (proporção de um para 30 aves) tipo copo de pressão infantis por gaiola, com capacidade de meio litro, trocando-se a água era trocada duas vezes ao dia. Aos 14 dias, os bebedouros copo de pressão infantis foram substituídos por bebedouro tipo calha instalado nas laterais de cada gaiola.

Nos primeiros sete dias, as aves foram alimentadas em comedouro tipo bandeja, sobre o qual colocouse tela plástica com malha de $1 \mathrm{~cm}$, visando a redução do desperdício de ração. A partir dos sete dias, as aves foram alimentadas em comedouros tipo cone de pressão para pintainhas de postura, foram equipados com molas metálicas, para se evitar desperdício de ração e, após 14 dias, a ração foi fornecida em comedouros lineares. Durante o período experimental (42 dias), as aves receberam ração e água à vontade. Foi fornecida três vezes ao dia ração à base de milho e farelo de soja, formulada segundo recomendações do NRC (1994) para codornas em fase de crescimento
(Tabela 1). Semanalmente, foram pesadas as eventuais sobras, para obtenção do consumo de cada parce1a. As aves receberam fotoperíodo de 24 horas diárias de luz. As cortinas do galpão eram reguladas conforme a necessidade de conforto das aves. Semanalmente, as aves de cada gaiola eram pesadas, para cálculo do peso da parcela, e contadas, para controle da mortalidade. $\mathrm{O}$ registro da mortalidade das aves foi anotado em ficha técnica no dia do evento.

Aos 42 dias de idade, foram amostrados, ao acaso, 10 machos por parcela, perfazendo 40 machos por tratamento, para avaliação do rendimento de carcaça e dos cortes cárneos. As aves foram identificadas individualmente com anéis numerados nas patas e submetidas a um período de jejum alimentar de oito horas, com água à vontade até o momento do carregamento. As aves foram transportadas em caixas apropriadas e conduzidas até $\mathrm{o}$ abatedouro experimental, onde foram realiados o abate e a avaliação de carcaça, segundo metodologia descrita por Oliveira (2001).

Tabela 1 - Composição percentual da ração experimental Table 1 - Percent composition of the experimental ration

\begin{tabular}{lc}
\hline $\begin{array}{l}\text { Ingrediente } \\
\text { Ingredient }\end{array}$ & $\begin{array}{c}\text { Período de } 1 \text { a } 42 \text { dias } \\
\text { Period from } 1 \text { to } 42 \text { days }\end{array}$ \\
\hline Milho (Corn) & 52,33 \\
Farelo de soja (Soybean meal) & 42,85 \\
Óleo de soja (Soybean oil) & 1,916 \\
Calcário (Limestone) & 1,068 \\
Sal (Salt) & 0,350 \\
Fosfato bicálcico (Dicalcium phosphate) & 0,950 \\
Suplemento vitamínico e mineral* & 0,300 \\
Vitamin and mineral supplement & \\
DL-metionina (DL-methionine) & 0,134 \\
Colina (Choline) & 0,090 \\
\hline Total (Total) & 100,00 \\
\hline Nutriente (Nutrient) & 24.00 \\
Proteína bruta (\%) (Crude protein, \%) & 2900 \\
Energia metalizavel (kcal/kg) (ME, kcal/kg) & 0,800 \\
Cálcio (\%) (Calcium, \%) & 0,300 \\
Fósforo disponível (\%) & \\
Available phosphorus (\%) & 0,500 \\
Metionina (\%) (Methionine, \%) & 0,870 \\
Metionina + Cistina & \\
Methionine + Cystine & 1,320 \\
Lisina (\%) (Lysine, \%) & \\
* Composição dos suplementos vitamínicos e mineral (Composition \\
of vitamin and mineral supplement): Ácido fólico (Acid folic) 700 mg; \\
Ácido pantotênico (Panthotenic acid) 13.000 mg; Antioxidante \\
(Antioxidant) 0,50 mg; Niacina (Niacin) 35.000 mg; Se 300 mg; Vit. \\
A 7.000.000 Ul; Vit. B1 1.600 mg; Vit.B12 10.000 mg; Vit B2 \\
5.000 mg; Vit. B6 2.600 mg; Vit. D3 1.500.000 Ul; Vit. E 12.000 \\
mg; Vit. K3 1.500 mg; Cu 16.000 mg; Fe10.000 mg; I 1.500 mg; \\
Mn150.000 mg; Zn 100.000 mg. \\
\end{tabular}


O delineamento experimental utilizado foi inteiramente casualizado, com quatro tratamentos (quatro grupos genéticos A, B, C e D) e cinco repetições de 60 aves cada. A análise dos resultados, assim como a confecção dos gráficos, foi realizada conforme os procedimentos estabelecidos no General Linear Model do SAS® (SAS Institute, 1989). Para comparação entre médias, foi realizado o teste Tukey, utilizando como nível de rejeição alfa igual a 0,05.

\section{Resultados e Discussão}

No decorrer do período experimental, a temperatura média registrada no interior do galpão foi de $23^{\circ} \mathrm{C}$ e a umidade relativa do ar, de $69,5 \%$, sugerindo que as aves não sofreram estresse térmico e, portanto, seu desempenho não foi afetado por essa variável.

Os resultados de peso médio, ganho médio de peso, consumo médio de ração, conversão alimentar e mortalidade no período de 1 a 42 dias estão apresentados na Tabela 2.

Constatou-se diferença estatística $(\mathrm{p}<0,05)$ para peso médio e ganho médio de peso aos 42 dias de idade entre os grupos genéticos estudados. O grupo genético $\mathrm{C}$ apresentou médias superiores em relação aos demais grupos. Esses resultados estão em conformidade com Oguz et al. (1996), que observaram diferenças significativas para peso médio inicial em duas linhagens de codornas japonesas, uma selecionada, durante cinco gerações, para ganho de peso e outra não-selecionada para mesma característica. No entanto, Oliveira (2001) não observou diferenças estatísticas para a mesma característica entre os grupos genéticos de codornas para produção de carne. Os pesos médios obtidos nesse experimento foram supe- riores aos encontrados na literatura (Hyanková et al., 2002; Marks, 1993; Marks, 1980), o que pode ser explicado pela diferença no peso dos ovos de linhagens de codornas especializadas na produção de carne e de linhagens voltadas para produção de ovos.

Os efeitos de linhagem ou grupo genético sobre as características de peso são bem documentados mesmo entre aves de mesmo tipo (Caron et al., 1990; Marks, 1993; Oguz et al., 1996).

Nas últimas semanas de vida, pode-se observar que as aves apresentaram redução no ganho de peso (Figura 1), o que também foi observado por Almeida (2001). Esse fato é bem relatado por Macari et al. (1994), que explica que, no animal jovem, ocorre maior deposição muscular, ou seja, maior ganho de peso. Quando o animal se torna adulto, a deposição muscular e o crescimento ósseo diminuem, ocasionando redução geral na taxa de ganho de peso.

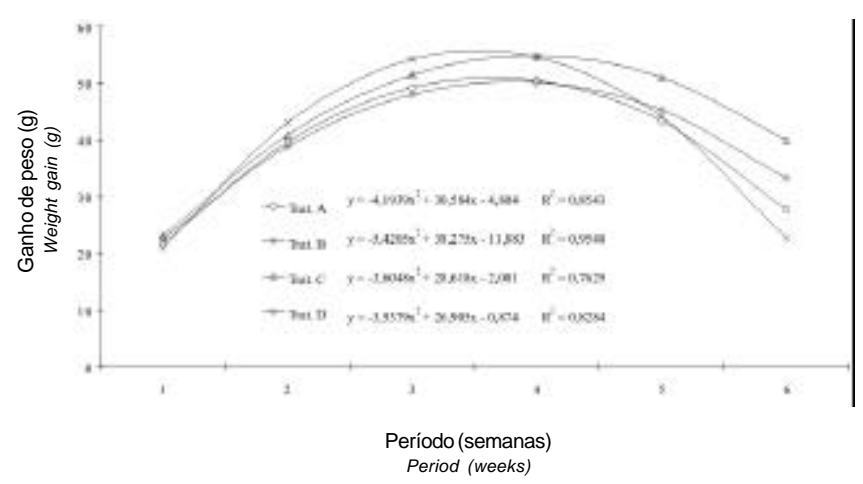

Figura 1 - Curva ajustada de ganho médio de peso (g) por período de quatro grupos genéticos de codornas para produção de carne.

Figure 1 - Adjusted curve of body weight gain $(g)$ of four genetic groups of meat quail.

Tabela 2 - Desempenho de quatro grupos genéticos de codornas para produção de carne de 1 a 42 dias Table 2 - Performance of four genetic groups of meat quail from 1 to 42 days of age

\begin{tabular}{lccccc}
\hline $\begin{array}{l}\text { Grupos genético } \\
\text { Genetic group }\end{array}$ & $\begin{array}{c}\text { Peso corporal }(\mathrm{g}) \\
\text { Body weight }(\mathrm{g})\end{array}$ & $\begin{array}{c}\text { Ganho de peso }(\mathrm{g}) \\
\text { Weight gain }(\mathrm{g})\end{array}$ & $\begin{array}{c}\text { Consumo de ração }(\mathrm{g}) \\
\text { Feed intake }(\mathrm{g})\end{array}$ & $\begin{array}{c}\text { Conversão alimentar } \\
\text { Feed conversion }\end{array}$ & $\begin{array}{c}\text { Mortalidade (\%) } \\
\text { Mortality }(\%)\end{array}$ \\
\hline $\mathrm{A}$ & $240,88^{\mathrm{b}}$ & $231,89^{\mathrm{b}}$ & 699,99 & 3,02 & 12,50 \\
$\mathrm{~B}$ & $248,26^{\mathrm{b}}$ & $239,20^{\mathrm{b}}$ & 731,13 & 3,06 & 14,60 \\
$\mathrm{C}$ & $269,36^{\mathrm{a}}$ & $260,94^{\mathrm{a}}$ & 742,94 & 2,85 & 15,02 \\
$\mathrm{D}$ & $246,04^{\mathrm{b}}$ & $237,82^{\mathrm{b}}$ & 701,84 & 2,95 & 10,84 \\
\hline Média (Mean) & 251,14 & 242,46 & 718,98 & 2,97 & 13,24 \\
CV $(\%)^{1}$ & 3,43 & 3,56 & 5,20 & 4,54 & 47,86 \\
\hline
\end{tabular}

1 Coeficiente de variação (Coefficient of variation).

$a, b$ Letras diferentes na mesma coluna indicam diferenças significativas $(p<0,05)$ entre os grupos genéticos.

$a, b$ Different small letters in the same column indicate significant differences $(p<.05)$ among genetic groups. 
O consumo médio de ração e a conversão alimentar não foram influenciados $(\mathrm{p}>0,05)$ pelos diferentes grupos genéticos, o que está de acordo com Oliveira (2001), que também não observou diferenças estatísticas para essas características. Entretanto, Marks (1993), estudando codornas japonesas com quatro semanas de idade, selecionadas e não-selecionadas para alto ganho de peso, encontraram diferenças entre linhagens para conversão alimentar. A partir da quarta semana de idade, as aves aumentaram o consumo de ração (Figura 2), ocasionando piora na conversão alimentar (Figura 3) o que foi favorecido pela intensa atividade das aves. Shrivastav \& Panda (1991), avaliando as variações de peso de 3 a 11 semanas de idade em codornas de corte alimentadas com níveis de 24 a 30\% de proteína bruta, observaram declínio na taxa de crescimento a partir da quinta semana, independentemente do nível protéico.

Nas condições em que este trabalho foi realizado, a variável mortalidade foi de difícil interpretação. Os coeficientes de variação foram extremamente altos durante o período de 1 a 42 dias, em decorrência da grande variação dentro dos tratamentos (Figura 4), indicando que, provavelmente, o fator considerado neste experimento (grupo genético) não foi o responsável pela mortalidade em codornas para produção de carne no período de 1 a 42 dias. Observou-se tendência de maior taxa de mortalidade durante a primeira semana, com declínio a partir da segunda semana de vida das aves. Porém, quando se estabeleceu a maturidade sexual das aves, grande parte da mortalidade resultou da insistência de cópula por parte dos ma-

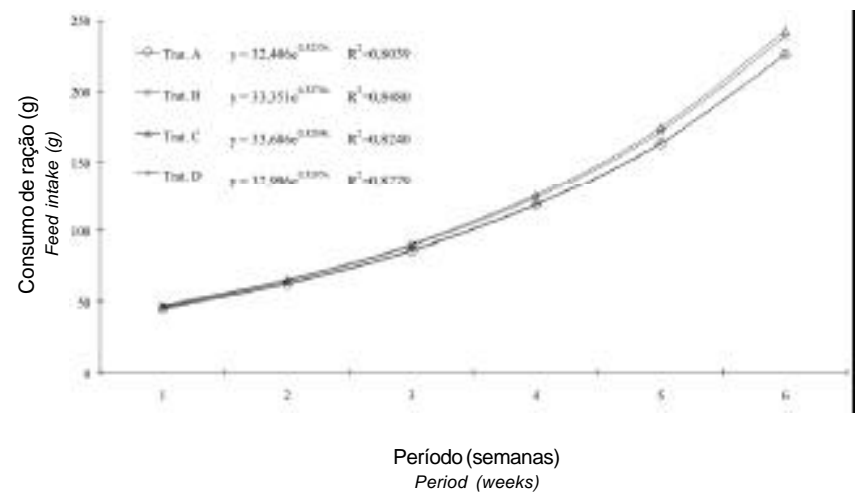

Figura 2 - Curva ajustada de consumo de ração (g) de quatro grupos genéticos de codornas para produção de carne.

Figure 2 - Adjusted curve of feed intake $(g)$ of four genetic groups of meat quail. chos, o que debilitou as fêmeas, favorecendo o evento. Essa observação sugere que, nos próximos estudos, as aves de sexos diferentes sejam alojadas separadamente (Figura 4).

As informações sobre peso vivo, peso de carcaça, rendimento de carcaça, porcentagens de dorso, asas, pernas, peito e carne de peito são apresentadas na Tabela 3.

Não foram encontradas diferenças significativas ( $p>0,05)$ para peso de carcaça entre os grupos genéticos estudados, sugerindo que as linhagens em estudo são geneticamente semelhantes. Esse resultado diverge de alguns trabalhos na literatura (Oliveira, 2001; Oguz et al., 1996), nos quais foi observado efeito do grupo genético sobre o peso de carcaça. Os

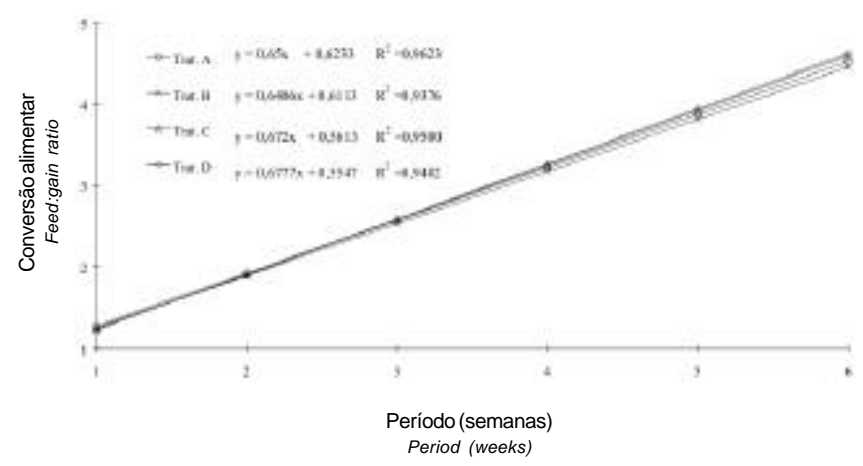

Figura 3 - Curva ajustada de conversão alimentar de quatro grupos genéticos de codornas para produção de carne.

Figure 3 - Adjusted curve of feed conversion of four genetic groups of meat quails.

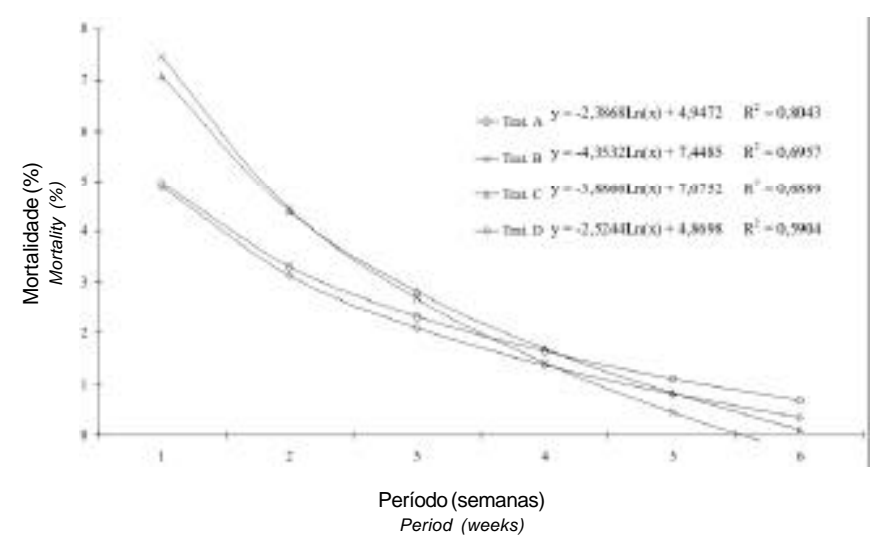

Figura 4 - Curva ajustada de mortalidade (\%) de quatro grupos genéticos de codornas para produção de carne.

Figure 4 - Adjusted curve of mortality (\%) of four genetic groups of meat quails. 
Tabela 3 - Rendimento de carcaça e dos cortes de quatro grupos genéticos de codornas macho aos 42 dias de idade, selecionadas para produção de carne

Table 3 - Carcass yield and cuts of four genetic groups of meat male quails males at 42 days of age

\begin{tabular}{|c|c|c|c|c|c|c|c|}
\hline $\begin{array}{l}\text { Grupo } \\
\text { genético } \\
\text { Genetic } \\
\text { group }\end{array}$ & $\begin{array}{c}\text { Peso } \\
\text { de carcaça }(\mathrm{g}) \\
\text { Carcass } \\
\text { weight }(g)\end{array}$ & $\begin{array}{c}\text { Rendimento } \\
\text { de carcaça }(\%) \\
\text { Carcass } \\
\text { yield }(g)\end{array}$ & $\begin{array}{l}\text { Asas (\%) } \\
\text { Wings }(\%)\end{array}$ & $\begin{array}{c}\text { Dorso }(\%) \\
\text { Back }(\%)\end{array}$ & $\begin{array}{c}\text { Pernas }(\%) \\
\text { Legs }(\%)\end{array}$ & $\begin{array}{l}\text { Peito }(\%) \\
\text { Breast }(\%)\end{array}$ & $\begin{array}{c}\text { Carne } \\
\text { de peito }(\%) \\
\text { Breast } \\
\text { meat }(\%)\end{array}$ \\
\hline B & 175,11 & 70,82 & $9,14^{\mathrm{b}}$ & $33,40^{\mathrm{a}}$ & $22,26^{\mathrm{b}}$ & 35,20 & $69,30^{\mathrm{b}}$ \\
\hline $\mathrm{C}$ & 179,46 & 70,47 & $9,37^{b}$ & $30,27^{b}$ & $24,26^{\mathrm{a}}$ & 36,10 & $71,25^{\mathrm{b}}$ \\
\hline Mean & & & & & & & \\
\hline $\mathrm{CV}(\%)^{1}$ & 10,23 & 5,43 & 11,66 & 11,19 & 8,72 & 8,33 & 10,64 \\
\hline
\end{tabular}

1 Coeficiente de variação (Coefficient of variation).

$a, b$ Letras distintas na mesma coluna indicam diferenças significativas $(p<0,05)$ entre os grupos genéticos.

$a, b$ Different small letters in the same column indicate significant differences $(p<.05)$ among genetic groups.

valores médios de carcaça encontrados neste estudo são superiores aos reportados na literatura (Móri et al., 2003; Almeida, 2001; Oliveira, 2001; Oguz et al., 1996).

Não houve diferença significativa $(p>0,05)$ para rendimento de carcaça entre os grupos genéticos, apesar de o grupo genético D apresentar discreta superioridade em sua média, como também foi relatado por diversos autores (Oliveira, 2001; Oguz et al., 1996; Caron et al., 1990). Porém, Móri et al. (2003) encontraram diferenças significativas entre machos de grupos genéticos de codornas para produção de carne.

Para rendimento de asa, são poucas as informações disponíveis na literatura. Nesse estudo, os grupos genéticos A e D foram estatisticamente diferentes $(\mathrm{p}<0,05)$ dos grupos $\mathrm{B}$ e $\mathrm{C}$, que obtiveram valores médios inferiores aos grupos A e D. Baumgartner et al. (1985) obtiveram valores médios semelhantes aos deste estudo, mas não constataram diferenças estatísticas entre linhagens para a mesma característica.

Foram encontradas diferenças significativas $(p<0,05)$ entre os grupos genéticos para porcentagem de dorso, com maior média para o grupo genético B. Baumgartner et al. (1985), comparando a composição da carcaça entre codornas para produção de ovos e de carne, não encontraram diferenças significativas para porcentagem de dorso, contudo, os valores obtidos por esses autores são inferiores aos deste estudo.

Foi observado efeito significativo $(\mathrm{p}<0,05)$ para porcentagem de pernas entre os grupos genéticos, de modo que os grupos genéticos $\mathrm{A}, \mathrm{C}$ e $\mathrm{D}$ obtiveram valores médios superiores ao grupo genético B. Esses resultados corroboram os obtidos por Oguz et al.
(1996) em linhagens japonesas selecionadas para ganho de peso às quatro semanas. Contudo, Móri et al. (2003) não encontraram efeito significativo $(p>0,05)$ para porcentagem de coxa de quatro grupos de codornas para produção de carne, obtendo valores muito similares aos deste estudo. Tserveni-Gousi \& Yannakoupolos (1986) obtiveram valores inferiores aos deste experimento em torno de $12 \%$ para porcentagem de coxa, talvez por estes autores terem estudado linhagens diferentes.

Neste ensaio, não foram detectadas quaisquer diferenças significativas $(\mathrm{p}>0,05)$ para porcentagem de peito, embora o grupo genético $\mathrm{C}$ tenha apresentado leve tendência de superioridade aos demais, o que está de acordo com observações realizadas por Oguz et al. (1996). Todavia, Móri et al. (2003), estudando características de carcaça de quatro grupos genéticos de codornas de corte, constataram diferenças significativas entre as linhagens para esta característica. A porcentagem média de peito para as linhagens estudadas foi de $35,32 \%$. Estudos indicam valores bastante variáveis para esta característica. Baumgartner et al. (1985) e Móri et al. (2003) reportaram valores médios superiores em até $14 \%$ aos obtidos nesta pesquisa.

Foram encontradas diferenças significativas $(p<0,05)$ para porcentagem de carne de peito entre os diferentes grupos genéticos avaliados; o grupo genético $\mathrm{D}$ apresentou média superior aos grupos $\mathrm{B}$ e $\mathrm{C}$, mas não diferiu estatisticamente do grupo genético A. Singh et al. (1980), estudando o rendimento de carne de peito em codornas japonesas aos 42 dias de idade, criadas em condições diferentes às deste ensaio, obtiveram, para carne de peito, médias superiores às deste trabalho. 


\section{Conclusões}

Nas condições de realização desta pesquisa, podese concluir que os grupos genéticos de codornas avaliados apresentam boa aptidão para para produção de carne, com diferenças em relação ao seu peso vivo e ao ganho médio de peso. Os grupos genéticos estudados apresentaram diferenças para porcentagem de pernas, asa, dorso e carne de peito. As variabilidades existentes para as características de desempenho e rendimento de carcaça das linhagens estudadas permitem trabalho de seleção e melhoramento genético para a produção de carne de codornas.

\section{Literatura Citada}

ALMEIDA, M.I.M. Efeito de linhagem e de nível protéico sobre o desempenho e características de carcaça de codornas (Coturnix sp) criadas para corte. Botucatu: Universidade Estadual Paulista, 2001. 96p. Tese (Doutorado em Melhoramento Genético) - Universidade Estadual Paulista, 2001.

ARDININGSASI, S.M.; MAEDA, Y.; OKAMOTO, S. et al. Comparative studies of body weight, tibia lenght and abdominal fat weight among lines selected for body size in japanese quail Coturnix coturnix japonica. Japanese Poultry Science, v.29, n.5, p.310-315, 1992.

BACON, W.L.; NESTOR, K.E. Divergent selection for body weight and yolk precursor in Coturnix coturnix japonica. 5 . Correlated responses in adult body weight, liver weight, ovarian follicle production and carcass composition of laying hens. Poultry Science, v.62, n.9, p.1876-1884, 1983.

BAUMGARTNER, J.; KOCIOVA, E.; POLANSKA, O. Carcass and nutritive value of japanese quail. Roczniki Naukowe Zootechniki, v.12, n.1, p.171-178, 1985.

CAMPION, D.R.; MARKS, H.L.; REAGAN, J.O. et al. Composition and muscle cellularity of japanese quail after selection for high body weight under an optimal or suboptimal nutritional environment. Poultry Science, v.61, n.2, p.212$217,1982$.

CARON, N.; MINVIELLE, F.; DESMARAIS, M. et al. Mass for 45 day body weight in japanese quail: selection response carcass composition, cooking properties, and sensory characteristics. Poultry Science, v.69, n.7, p.1037-1045, 1990.

GARCIA, E.A. Codornas para produção de carne. In: SIMPÓSIO INTERNACIONAL DE COTURNICULTURA, 1., 2002, Lavras. Anais... Lavras: 2002. p.97.

HYANKOVÁ, L.; DEDKOVÁ, L.; KNÍZETOVÁ, H. et al. Heterosis in body weight related to growth performance of parental lines of japanese quail and to heterosis in lay. British Poultry Science, v.43, n.4, p.508-517, 2002.

LEPORE, P.D.; MARKS, H.L. Growth rate inheritance in japanese quail: 4. Body composition follwing four generation of selection under different nutritional environments. Poultry Science, v.50, n.5, p.1191-1193, 1971.

MACARI, M. Fisiologia do crescimento. In: UNESP (Ed.) Fisiologia aviária aplicada a frangos de corte. 1.ed. Jaboticabal, 1994.p.296.

MARKS, H.L. Carcass composition, feed intake, and feed efficiency following longterm seletion for 4-week body weight in Japanese quail. Poultry Science, v.72, n.6, p.1005-1011, 1993.
MARKS, H.L. Feed efficiency changes accompanying selection for body weight in chickens and quail. World's Poultry Science, v.47, n.10, p.197-212, 1991.

MARKS, H.L. Abdominal fat and testes weight in diverse genetic lines of japanese quail. Poultry Science, v.69, n.10, p.1627-1633, 1990.

MARKS, H.L. Feed efficiency of selected and nonselected japanese quail lines. Poultry Science. v.59, n.1, p.6-10, 1980.

MICHALSKA, E.; KORZYNSKA-NOWAK, R. Growth of japanese quail in relation to generation, parentage and sex. Prace $\mathbf{i}$ Materialy Zootechniczne, n.42, p.91-101, 1992.

MÓRI, C.; PAVAN, A.C.; GARCIA, E.A. et al. A. Avaliação do rendimento de carcaça, peito e coxa de quatro grupos genéticos de codornas machos para corte. In: REUNIÃ̃ ANUAL DA SOCIEDADE BRASILEIRA DE ZOOTECNIA, 36., 2003, Santa Maria. Anais... Santa Maria: Sociedade Brasileira de Zootecnia/Gmosis, (2003) CD-ROM.

NESTOR, K.E.; BACON, W.L.; VELLEMAN, S.G. et al. Effect of selection for increased body weight and increased plasma yolk precursor on developmental stability in japanese quail. Poultry Science, v.81, n.2, p.160-168, 2002.

NATIONAL RESEARCH COUNCIL - NRC. Nutrient requirements of poultry. Washington: National Academy Press. 9.ed. 1994. 156p.

OGUZ, I.; ALTAN, O.; KIRKPINAR, F. et al. Body weights, carcass characteristics, organ weights, abdominal fat and lipid content of liver and carcass on two lines of japanese quail (Coturnix coturnix japonica), unselected and selected for four week body weight. British Poultry Science, v.37, n.3, p.579-588, 1996.

OLIVEIRA, E.G. Avaliação do desempenho, rendimento de carcaça e das características químicas e sensoriais de codornas para corte. Botucatu: Universidade Estadual Paulista, 2001. 96p. Tese (Doutorado em Zootecnia) - Universidade Estadual Paulista, 2001.

PANDA, B.; AHUJA, S.D.; SHRIVASTAV, A.K. et al. Quail production technology. Izatnagar: Central Avian Research Institute, 1987. 31p.

STATISTICAL ANALYSES SYSTEM - SAS. User's guide: statistics. Cary: 1989.

SHRIVASTAV, A.K.; PANDA, B. Distribution of fat at different locations as influenced by dietary calory - protein ratio and energy levels in quail broilers. Indian Veterinary Medical Jounal, v.15, n.3, p.178-184, 1991.

SINGH, R.P.; SIRVASTAV, A.K.; PANDA, B. Meat yield of japanese quail (Coturnix coturnix japonica) at different stages of growth. Indian Journal Poultry Science, v.16, p.119$125,1980$.

STEIGNER, J.W., NESTOR, K. E.; LILBURN, M.S. Growth and development of lines of japanese quail (Coturnix coturnix japonica) divergently selected for body weight at 4 weeks of age. Comparative Biochemistry and Phisiology, v.102, n.2, p.389-393, 1992.

TOELLE, V.D.; HAVENSTEIN, G.B.; NESTOR, K.E. et al. Genetic and phenotipc relationships in Japanese quail. 1. Body weught, carcass and organ measurements. Poultry Science, v.70, n.8, p.1679-1688, 1991

TSERVENI-GOUSI, A.S; YANNAKOPOULOS, A.L. Carcase characteristics of japanese quail at 42 days of age. British Poultry Science, v.27, p.123-127, 1986.

Recebido em: 05/03/04 Aceito em: 06/04/05 